\title{
Kant on the Transcendental Deduction of Space and Time: an Essay on the Philosophical Resources of the Transcendental Aesthetic
}

\author{
MELISSA McBAY MERRITT \\ University of New South Wales
}

I.

Commentary on Kant's Critique of Pure Reason has focused intensively on the transcendental deduction of the categories - the pivotal chapter of the book that governs our understanding of much that precedes it and just about all that follows it. One simple way to understand the systematic function of the Transcendental Deduction is to appreciate that it provides an account of how the 'two stems of human knowledge' (A15/B29) - sensibility and understanding - must relate to one another in the production of knowledge. ${ }^{1}$ On Kant's view, these capacities are distinguished by their radically different modes of representation: intuition and concept. Although sensibility and understanding are fundamentally distinct - they 'cannot exchange their functions' - they must nevertheless cooperate in the production of knowledge: 'Only through their unification can cognition arise' (A51/B75-6). The task of the Deduction is to show how the categories - concepts that stem from the 'nature of the understanding' alone - apply necessarily to objects that can only be given in experience, and represented as given through sensible intuition. ${ }^{2}$

Yet my concern in this paper lies not with the details of the transcendental deduction of the categories, but rather with Kant's remarks about a transcendental deduction of 'the concepts of space and time'. In the preamble to the transcendental deduction of the categories, Kant announces:

We have above traced the concepts of space and time to their sources by means of a transcendental deduction, and explained and determined their a priori objective validity. (\$13, A87/B119-120) 
What is this transcendental deduction, and what is its relation to the more widely examined transcendental deduction of the categories? ${ }^{3}$ Kant's remark startles: the designation of this transcendental deduction occurs ex post facto. We may safely infer that Kant here points back to the Transcendental Aesthetic, as there is simply no other prior part of the book that could conceivably contain a transcendental deduction of the concepts of space and time.

Otherwise, Kant's stunner leaves only a tangle of questions in its wake. Is this transcendental deduction carried out in one distinct part of the Aesthetic, or is it the upshot of the Aesthetic in its entirety? Commentators have offered a variety of inconclusive answers to this question - to the extent that they have addressed the issue at all. ${ }^{4}$ And why does Kant refer here to the concepts of space and time, when the Aesthetic is supposed to have established that space and time are pure intuitions? And what, exactly, is a transcendental deduction of the concepts of space and time? Is it strictly analogous to the transcendental deduction of the categories, or are there instead significant differences? ${ }^{5}$

The only interpretative guidance Kant offers lies in the suggestion that this transcendental deduction would have addressed the 'a priori objective validity' of space and time. This bit of guidance, however, only sharpens our view of the interpretative challenges at stake. For there is good reason to doubt that Transcendental Aesthetic should possess the philosophical resources to yield claims about the objective validity of our representations. Later remarks in the Transcendental Deduction give rise to such doubt, at any rate. There Kant claims that 'the unity of consciousness is that which alone constitutes the relation of representations to an object, [and] hence their objective validity; and consequently that they become cognitions' $(\$ 19, \mathrm{~B} 137)$. Kant accounts for the 'unity of consciousness' through the identification of a principle - the principle of the synthetic unity of apperception - which is first revealed in $\$ 16$ of the Deduction. Therefore, if the transcendental deduction of a concept is the account of its a priori objective validity, how could there have been a transcendental deduction of the concepts of space and time before having the principle of the synthetic unity of apperception in hand? Given its primary position in the order of exposition, it does not seem that the Transcendental Aesthetic can establish anything about the objective validity of the concepts of space and time. Perhaps this business about their transcendental deduction of space and time is nothing more than a slip of the pen. 
However, I do not think that Kant's pen has slipped there - and, at any rate, basic principles of exegesis require us to see if the apparently conflicting claims might be brought into stable equilibrium. The conflict at issue concerns the philosophical resources of the Aesthetic: whether they are sufficient to yield claims about the objective validity of our representations. Such assessment of the philosophical resources of the Aesthetic is a prerequisite for arriving at an adequate understanding of the systematic relation between the Aesthetic and the Deduction - how, that is, the Deduction may draw upon the results of the Aesthetic. Does the Deduction's account of the objective validity of the categories depend upon the Aesthetic's account of the objective validity of space and time? Or is it the case that nothing can be established about the objective validity of space and time prior to the transcendental deduction of the categories? And if we take the latter position, how are we to interpret Kant's remarks about a transcendental deduction of the concepts of space and time?

My aim in this paper is to explain Kant's retrospective remark about a transcendental deduction of space and time, and hence to address the sense in which the Aesthetic can provide an account of their objective validity. My account shall proceed from two interpretative presuppositions. The first concerns the notion of 'objective validity' itself. I take it that the notion of objective validity applies properly to concepts: to establish that a concept is objectively valid is to account for its applicability to some real (empirical) object, and hence for its figuring in our knowledge of such objects. If the notion of 'validity' tracks the legitimacy of our applying certain representations, then this notion should pertain to concepts but not intuitions, since the latter are actualizations of our receptivity and thus are not happily thought of as being applied. Hence it will be important, in what follows, to distinguish between the concepts of space and time and the intuitions of space and time.

My second presupposition has more to do with general interpretative methodology. I have raised a question about the philosophical resources of the Aesthetic - whether they are sufficient to yield claims about the objective validity of our representations, and specifically the concepts of space and time. It is the transcendental deduction of the categories that teaches us that this might be an issue at all. ${ }^{6}$ Nevertheless, this question about the philosophical resources of the Aesthetic requires us to examine the Aesthetic on its own terms, fully appreciating its primary place in the order of exposition. ${ }^{7}$ In this paper, I wish to consider what 
argumentative resources are both available in the Aesthetic, and actually employed there. As I will suggest later on, my resolute adoption of this interpretative principle distinguishes my account from that of other commentators.

\section{2.}

In order to provide any account of the significance of the Aesthetic's transcendental deduction, we must examine the Aesthetic in some detail - though an exhaustive reading lies outside of the scope of this paper. My aim is to shed light on the nature of its arguments in order to explain, ultimately, just what a transcendental deduction of space and time is supposed to achieve, and how the Aesthetic manages to achieve it. I shall begin in this section $(\mathbb{2})$ with the Aesthetic's opening remarks regarding a hylomorphic distinction to be drawn with regard to intuition. This will help us to ascertain the general aim of the Aesthetic, which will in turn provide general interpretative guidance for the rest of the account. The bulk of my account $(\mathbb{S} \mathbb{S} 3-5)$ shall address the fact that the primary task of the Aesthetic is to provide an 'exposition' of the concepts of space and time. Clarification of just what sort of account an 'exposition' is meant to provide will then enable us to locate the transcendental deduction precisely in the text of the Aesthetic, as well as to appreciate what this deduction achieves and why it is required (\$S $\left.\int 6-7\right)$.

The aim of the Aesthetic can be drawn out of Kant's initial proposal to distinguish between the 'matter' and 'form' of appearances:

In appearance I call that which corresponds to the sensation its matter, but I call that which makes it that the manifold of appearance can be ordered in certain relations the form of appearance. Since that in which alone sensations can be ordered, and placed in a certain form, cannot itself in turn be sensation, so the matter of all appearance is only given to us a posteriori, but its form must all lie ready for it in the mind a priori, and can therefore be regarded separately from all sensation. (A20/B34)

Claiming that sensation cannot itself order sensation, and noting that sensation is of course 'given to us a posteriori', Kant baldly asserts that the form of appearance - its ordering principle - must lie 'in the mind a priori'. Is this supposed to be an argument? If so, it fails. For even if we grant the apparent premise that sensation must be orderable, we are left 
wanting some warrant for the inference from the a posteriori nature of sensation (matter) to the a priori nature of the form. Nothing has been said to rule out the possibility of an a posteriori form.

Now, it is possible that Kant does not take himself to be offering an argument here - I will return to that in a moment. First it is worth pausing to take note of a further development. The hylomorphism thesis, as inadequately defended as it is, provides the platform for what appears to be an announcement of the investigative programme of the Aesthetic. ${ }^{8}$ The hylomorphism thesis allows us to suppose that we may start with a composite representation, and strip away whatever is contributed by the intellect, as well as 'everything that belongs to sensation, so that nothing but pure intuition and the mere form of appearances remains, which is the sole thing that sensibility yields a priori' (A22/B36; see also A20-1/B35). Kant speaks in the definite future here: 'we will' carry this out 'in the Aesthetic' (A22/B36). Yet the simple fact is that this abstraction procedure is not carried out in the Aesthetic; Kant rather seems to treat these remarks as if they were a performative speech act, achieving directly through the uttering. Moreover, it is hard to see how this abstraction procedure could be carried out in any systematic way at this point in the book, since we do not yet have in place the official story about what the understanding contributes to appearances: we could hardly be expected to know, for the purposes of a 'science of all a priori principles of sensibility' (A21/B35), what is to be removed at each stage.' Undeterred, Kant continues: 'It will be found in this investigation, that there are two pure forms of sensible intuition as principles of a priori cognition, namely space and time, with the assessment of which we now occupy ourselves' (A22/B36). But rather than working through the abstraction procedure that the hylomorphism thesis seemed, at least partially, to underwrite, we are instead ushered on to the exposition of space and time - without any initial justification that these are the representations with which we ought to be concerned.

These puzzles about what Kant is up to in the Aesthetic - and what he takes himself to be up to in the Aesthetic - confront us from the start. I would like to suggest that the hylomorphism thesis has already been argued for in the Critique's front matter, though in a preliminary and provisional fashion.

The front matter is largely concerned with clarifying the operative conception of the faculty of reason, the subject of critical self-assessment. The relevant conception of reason is drawn from a view of the metaphysical impulse that Kant attributes to the 'peculiar fate' of human 
reason (Avii): in metaphysics, reason 'determines its object wholly a priori' $(\mathrm{Bx})$. This is taken to be the fundamental claim of reason, which Critical philosophy aims to vindicate. Specifically at stake is reason's capacity for theoretical cognition, in which it merely determines its object without also making the object actual (Bix) ${ }^{10}$ In other words, the objects of theoretical cognition exist independently of the cognition itself; the cognition of these objects must therefore represent them in a manner that respects this independence. Hence Kant suggests that reason would need to incorporate a receptive capacity as one of its elements: this receptive capacity (sensibility) makes a distinct, and necessary, contribution to theoretical cognition - and, specifically, to a priori theoretical cognition.

The vindication of the claim of reason would require that we show how it could be possible to determine something about these objects prior to their being actually given - prior, that is, to their being perceived - but without losing sight of their status as objects that must be able to be represented as given in order to be known at all. The cognition in question would require representations that are a priori, and yet are also actualizations of our receptivity. Thus an a priori receptive capacity would figure as an element of pure theoretical reason: to suppose otherwise would close down the project of accounting for our capacity to make claims that hold of necessity and yet pertain to matters of fact (i.e. to judge synthetically and a priori). The front matter then concludes by pointing to the distinct task of a transcendental aesthetic: the account of the representations that would 'constitute the condition under which objects are given to us' (A15/B29-30). In this manner, the front matter concludes with what Kant refers to as a 'preliminary' that professes only to point out what would need to be established about human sensibility if the claim of reason were to be vindicated.

The opening section of the Aesthetic - with its perfunctory account of hylomorphism - may, in turn, be interpreted as simply refining our view of what would need to be established in a transcendental doctrine of sense. After all, it is puzzling on the face of it: how can there be $a$ priori sensible representations, given that sensible representation would seem to require that the mind is somehow affected? Hylomorphism is introduced as a possible key to the solution: the matter of sensible representation is whatever corresponds to the physical affection, but the form is the condition of the possibility of our sensible consciousness of the matter. The hylomorphism thesis is anchored in Kant's initial presentation of the claim of reason: it clarifies something about the 
overall framework of the critical investigation - the investigation that aims to vindicate the claim of reason. The hylomorphism thesis does not require a knock-down argument at the outset of the Aesthetic; it may be admitted as a proposal on the ground that the critical investigation could not get underway without it.

But we have to be careful how we interpret the hylomorphism thesis. One might suppose that the hylomorphism thesis simply draws on the intuitive point that, for example, no sound could register in our consciousness if it had no duration in time, and no colour could register in our consciousness if it had no extension in space. The representations of space and time seem to be required in order for the matter of sensation to show up for us at all; hence 'the matter of all appearance' depends upon a form that would 'lie ready for it in the mind a priori' (A20/B34). This way of interpreting the hylomorphism turns on a claim about the role of pure forms of intuition in the conscious enjoyment of sensation. However, it does not seem to possess the resources to address the role that these forms might play in allowing sensation to figure in knowledge of objects. It does not, for example, distinguish between the case of my seeing a spatially extended white page before me, and my enjoying the extension of a rhapsodic blotch of colour upon closing my eyes.

Since the hylomorphism thesis is anchored in Kant's presentation of the Critical project as one that promises to vindicate the claim of reason, we must interpret that thesis in a manner that is consonant with that aim. Kant promises that the Aesthetic will show that there are 'two pure forms of sensible intuition as principles of a priori cognition, namely space and time' (A22/B36, emphasis added). So when we admit the hylomorphism thesis on the ground that it simply clarifies something about the general framework of the Critical project, it is already thereby supposed that these 'pure forms of sensible intuition' would play a necessary role in the cognition of objects. We cannot yet say that there really are such forms; we cannot even say what it would really mean for there to be such forms. But we might get some handle on the idea by noting that, for example, the apparent spatiality of our rhapsodic blotch is not intersubjectively accessible. By contrast, when we think of a representation's playing a necessary role in the cognition of objects, what matters is that representation's capacity to put us on to intersubjectively accessible features of things. Space, as a pure form, must be like that.

At this point in the Aesthetic, no positive steps have been taken toward an account of the relevant notion of a 'pure form of sensible intuition'. So far, we can only say that the required account of these pure 
forms should establish their status as necessary conditions of the cognition of objects. Thus, when the Aesthetic claims to offer an account of the a priori constitution of human sensibility - the 'constant form' of our receptivity (A27/B43) - this must be interpreted so that the pure forms of intuition should be accounted for as sources of cognition. I now set out to show how the Aesthetic can offer such an account. Clarification of this (broadly methodological) issue will prepare us to account for the transcendental deduction of space and time at the end.

3.

After the introduction of the hylomorphism thesis, Kant moves abruptly to the 'expositions' of the concepts of space and time. It will be helpful first to appreciate the general structure of the Aesthetic, which I represent in the following table; the section headings listed are Kant's own, except what appears in brackets.

Table 1: Organization of the Transcendental Aesthetic

\begin{tabular}{|c|c|}
\hline $\begin{array}{l}\text { \$2: Metaphysical Exposition of } \\
\text { this Concept [i.e. space] }\end{array}$ & $\begin{array}{l}\mathbb{S} \text { : Metaphysical Exposition of } \\
\text { the Concept of Time }\end{array}$ \\
\hline $\begin{array}{l}\text { \$3: Transcendental Exposition } \\
\text { of the Concept of Space }\end{array}$ & $\begin{array}{l}\mathbb{S 5} \text { : Transcendental Exposition } \\
\text { of the Concept of Time }\end{array}$ \\
\hline $\begin{array}{l}\text { [unnumbered section of } \\
\text { commentary on the exposition } \\
\text { of space, A26-30/B } 42-45]\end{array}$ & $\begin{array}{l}\mathbb{} 6: \text { section of commentary on } \\
\text { the exposition of time }]\end{array}$ \\
\hline
\end{tabular}

In this section, I will consider what 'exposition' involves, according to Kant. In subsequent sections $(\mathbb{S} \mathbb{S} 45)$, I will address the distinct but complementary functions of the Metaphysical and Transcendental Expositions, ${ }^{11}$ in preparation for addressing our question about what the Aesthetic can establish regarding the objective validity of space and time (\$S $\left.\int 6-7\right)$.

Let me begin with this overview, which looks ahead to the rest of my account. As we can see from the table above, the expositions concern the concepts of space and time. This is the case even though the Aesthetic 
aims to show that space and time are intuitions. Many commentators have simply supposed that Kant must be using the term 'concept' in some broader sense, to refer to 'representation' in general. ${ }^{12}$ Recently, Lorne Falkenstein, has argued that the point of the expositions is to show that the concepts of space and time refer to intuitions of space and time. ${ }^{13}$ I endorse his overarching interpretative suggestion wholeheartedly; however, since I disagree on many further matters of interpretation, I will provide my own argument, in the following sections, for the claim that the Metaphysical and Transcendental Expositions together show that the concepts of space and time refer to pure intuitions of space and time. ${ }^{14}$ Once that account is in place, we will see how a claim about the objective validity of the concepts of space and time follows as a direct consequence of the expositions.

In labeling the central stretch of the Aesthetic 'exposition', Kant indicates that its task is to present the content of the concepts of space and time:

By exposition (expositio) I understand the clear (even if not the complete) representation of that which belongs to a concept; an exposition is metaphysical if it contains that which exhibits the concept as given a priori. (A23/B38)

While exposition per se presents the content of a concept, metaphysical exposition presents the content of concepts that are 'given a priori'. ${ }^{15}$ Since we are concerned here with the argumentative strategies of the Aesthetic, it is worth mentioning that exposition differs from definition. According to Kant, there can be no analytic definitions of given concepts, since there is no way to establish that an exhaustive account of the content has been provided (Logic $\$ 104,9: 142$ ). This point is reiterated in the Critique's Doctrine of Method, at least with respect to concepts that are 'given a priori' such as 'substance, cause, right, equity': 'strictly speaking', they cannot be defined (A728/B756).${ }^{16}$ For this reason, Kant continues, the term 'exposition [Exposition]' should be preferred to the overly strong 'definition': the exposition of a concept can be admitted as 'valid to a certain degree' even if it does not provide an exhaustive treatment of the content of a concept (A729/B757). ${ }^{17}$

The main work of the Aesthetic is divided into Metaphysical and Transcendental Expositions. The Metaphysical Exposition, I will argue, presents an analytic exposition of the concepts of space and time. Concept analysis, I take it, proceeds by our reflecting upon the usage of 
a concept in a conceptual scheme. So, for example, the content of the concept of a certain theoretical entity may be exposited by considering its place, and corresponding entailment relations, in the scientific model in which it figures. I choose this non-ordinary example in order to emphasize that concept analysis does not, by itself, show that the concept refers to something that really exists: the concept may turn out to have nothing real corresponding to it at all. ${ }^{18}$

I will argue that the two stages of the exposition of the concepts of space and time address these issues in turn. That is, the Metaphysical Expositions explain what is thought in the concepts of space and time, by reflecting upon certain facts about our usage. They reveal that our usage reflects our commitment to the idea that the concepts of space and time refer to pure intuitions of space and time. However, the Metaphysical Expositions do not establish the legitimacy of these concepts: our commitment to the idea that space and time are pure intuitions could be unfounded. The Transcendental Expositions, then, show that the concepts of space and time - as presented in the Metaphysical Expositions - do indeed refer to something real, something that actually exists. However, this conclusion must be handled with care. For the concepts of space and time do not refer to objects in any ordinary sense, but rather to intuitions lying 'in the mind a priori' (A20/B34); and so, as we will see, the account of their objective validity (and hence their 'transcendental deduction') must fully acknowledge this point.

Before going on to examine the Metaphysical and Transcendental Expositions in any detail, I would like to indicate some of the ways in which my approach differs from that of other commentators. One point of difference is that my account takes more seriously than most Kant's presentation of the central task of the Aesthetic as 'exposition' the 'representation of that which belongs to a concept'. In my précis above, I noted that the Metaphysical Exposition provides an analytic exposition, which is to say that its central task is concept analysis. But then a further question naturally arises regarding the status of the Transcendental Exposition: in what sense does it continue the project of exposition, defined by Kant as representing what 'belongs to a concept'? On my view, the Transcendental Exposition does continue the project of showing what 'belongs' to the concept in question; but its claim is not an analytic one, drawn merely from reflection upon facts about our usage. ${ }^{19}$ At this point, I can only flag the issue, which I will explore when the discussion turns to the Transcendental Exposition $(\mathbb{\$} 5)$. 
Another point of difference between my account and that of many other commentators stems from my resolution to interpret the Aesthetic in a manner that is consonant with its primary place in the Critique's order of exposition. My intention is to acknowledge fully what is actually there on the page in the Aesthetic, and to avoid the temptation to supply supporting arguments that draw from developments that occur only later in the Critique. ${ }^{20}$ As we will see, Kant's remarks in the Metaphysical Exposition are terse in the extreme. This has led commentators to supply the arguments that they suppose are standing behind the scenes.

What these supplied arguments are supposed to achieve will of course depend upon the particular commentator's view of the argumentative burden of the Metaphysical Expositions: while many take this burden to be establishing the objective validity of space and time, more recently Daniel Warren has argued that this burden is only to establish the a priori origin of space and time. So, Warren takes each numbered paragraph of the Metaphysical Exposition of space to provide an 'apriority argument': each shows that the representation of spatial relations depends upon, and hence has its origin in, the representation of space itself. He then focuses entirely on what he refers to as the 'first a priority argument' (the first numbered paragraph), supplying the missing argument. ${ }^{21}$

With Warren, I agree that it is not the task of the Metaphysical Exposition to establish the objective validity of space and time; as I will argue, this is established only in the sections of commentary that follow the expositions. And as long as the argumentative burden of the Metaphysical Expositions is correctly appreciated, there can be no harm in commentators' supplying the arguments that Kant might have failed to provide: Warren's account of the first apriority argument can be accepted as an argument for an important feature of our concept of space. ${ }^{22}$ Yet whatever arguments commentators may supply to occupy the silences of the Metaphysical Exposition, they can do nothing more than account for the content of our concepts of space and time. They cannot establish the legitimacy of these concepts. So, in saying this, I am simply pointing out that I am asking a broader question from the one that Warren considers. And given that Kant takes the Aesthetic to establish sensibility's status as a cognitive capacity, I might add that this other question - about the legitimacy of our concepts of space and time, and their objective validity - is paramount. ${ }^{23}$ 
4.

Having taken note of what Kant understands by 'exposition', we anticipate an analysis of the concepts of space and time in the Aesthetic. (To avoid repetition and to keep my remarks to a manageable length, I will consider only space.) In concept analysis, we typically consider how we use the concept in question. One relevant feature of our usage is that we say that we represent things in space. The task of the Exposition is to clarify what this and other facts about our usage reveal about the content of the concept of space. The Metaphysical Exposition divides into four numbered paragraphs, which I will refer to as 'moments' of the exposition.

In the first moment, Kant sets out with the denial that space is 'an empirical concept that has been drawn from outer experiences' (A23/ B38). The claim appears to be based on the following remark:

For in order for certain impressions to be related to something outside of me (i.e. to something in another region of space from that in which I find myself), and, by the same token, in order for me to represent them as outside and next to one another, thus not merely as different but as in different places, the representation of space must already lie at the basis of this. (A23/B38)

Here Kant talks about representing things in various regions of space, as well as attributing to things certain relational spatial predicates. He claims that the representation of space itself 'lies at the basis' of these ways of representing.

Although Kant does begin with a negative claim about how the representation of space arises - inasmuch as it is not an empirical concept, it would not arise through abstraction upon particular 'outer experiences' - Kant does not seem to have offered a positive, apodictic argument for the a priori origin of the representation of space. Contrary to many commentators, I do not suppose that Kant even intends for the first moment to provide such an argument: at the very least, there is no demonstration there on the page. What we find instead better fits my interpretation, which is that Kant simply means to reflect broadly upon our usage of the concept of space - a task that will occupy him throughout the Metaphysical Exposition. ${ }^{24}$

If it makes sense to speak of a concept of space, then it should in turn make sense to speak of particular spaces, or places, that are appreciated 
as such in light of the general concept of space. There is something that it is to be a space; we can say that we are sitting in a particular space, and that we will get up and walk down the hall and find ourselves in a different space or place. A crucial fact about our usage of the concept of space is the following: when we take something to be $a$ space, or when we take something to have certain spatial properties, we ipso facto take it to be in space. Now, the sort of determination that I make when I recognize that $I$ am now in a different space from where I was ten minutes ago, or when I say that a certain bar of chocolate lies alongside my cup of tea, involves experience. In the first moment, Kant suggests that such determinations make a necessary reference to the representation of space itself, claiming that 'the representation of space must already lie at the basis' of such determinations.

Why should we suppose that the determination of particular spaces, or of particular spatial relations, requires the representation of space itself? This question is not fully answered in the first moment; the answer emerges gradually in the course of the Metaphysical Exposition. We do not yet have a very clear view of this requirement, or relation of dependence. The conclusion of the first moment - if we can so dignify it - is vague and gestural at best. Kant has offered nothing more than a reflection upon our usage, suggesting our commitment to the idea that the representation of space is prior - in some way that remains to be clarified - to the representation of particular spaces and the attribution of spatial properties and relations.

The second moment invokes the same vague idea that the representation of space 'lies at the basis' of the representation of particular spaces and the attribution of spatial properties and relations: space is 'a necessary a priori representation that lies at the basis of all outer intuitions' (A24/B38). There is not a new thought here; just a clarification that we take this relation of dependence - outer intuition's dependence upon the representation of space itself - to indicate that the representation of space is a priori. In support, Kant offers only the following: 'One can never have a representation of there being no space, even though one can very well think of there being no objects encountered in it' (A24/B38-9). We can consider a variety of objects represented as being in space, and remove them one by one; we would be left, Kant maintains, with the representation of space only now devoid of objects or outer appearances.

The second moment seems to be especially stipulative: there is no argument there on the page, only the assertion that we cannot represent 
the absence of space. This would be devastating if Kant were to take himself to establish here, in full certainty, that space is 'a necessary a priori representation'. However, on my reading the ambition of each moment in the Metaphysical Exposition is rather more modest: each moment simply aims to direct attention to some aspect of the content of the concept of space. What is said about the content of the concept of space must, of course, be made plausible; for as we noted above, Kant claims that the exposition of a concept must be admitted as 'valid to a certain degree' (A729/B757). But analytic exposition of a concept can do no more than reflect upon facts about usage in order to reveal what we are committed to in employing the concept as we do. Let us consider the rest of the Metaphysical Exposition to see if this interpretative suggestion holds up.

Throughout the Metaphysical Exposition, a basic fact about our usage of the concept of space is continually under consideration: that we speak of representing things in space. We think of particular spaces as being in space. Are such particular spaces parts of space? If so, are they constituent parts, or parts in some other sense? The third moment takes up these issues:

For, first, one can represent only one space, and if one speaks of many spaces, one understands by that only parts of one and the same unique space. Also, these parts cannot precede the one all-encompassing space, as its constituent parts (from which its composition would be possible), but rather they are only thought in it. (A25/B39)

When we represent a particular space, or a collection of particular spaces, we represent those spaces as in space; but these spaces do not 'precede the one all-encompassing space'. Does the third moment shed fresh light on the basic fact about our usage of the concept of space? Does it provide clarification of the still vague claim that the representation of space itself is prior to the representation of particular spaces, and the attribution of spatial predicates? Kant does at least refine our view of the basic fact about our usage: when we say we represent things in space, we mean that we represent things in 'the one allencompassing space'.

In order to appreciate the significance of this, let us return to the example of rhapsodic blotches of colour - the sort of thing one might see upon closing one's eyes. Certain spatial predicates may seem to apply to these blotches: one of these blotches can be bigger than another, or to 
the left of another, or alongside another, and so on. Although such spatial properties seem to apply to the rhapsodic blotches, still we cannot say that the blotches are in space: for they cannot be related to something in another region of space from the one that $\mathrm{I}$ am in. This is because they are not located in any determinate space at all. One rhapsodic blotch may stand in a certain relative 'distance' to another rhapsodic blotch, but it does not stand in any determinate distance to the tree outside my window. Outer intuitions are represented as being in space, rather than as merely having certain spatial (or quasi-spatial) properties. $^{25}$ And the representation of space itself is importantly different from these predicates - different in some way that is yet underdetermined, but that has something to do with meeting the requirements of cognition.

When we employ 'the universal concept of space in general' (A25/ B39), we are dealing with a general representation that may determine particulars. Hence we speak of various places or spaces; when we say of some particular that it is a space, we see it as being a thing of a certain kind, a determination governed by the universal concept of space. However, we do not suppose there to be spaceless 'gaps' in between these particulars, these spaces - distinguishing them from one another, but without the representation of intervening space. Rather, we take the various spaces to be parts of 'the one all-encompassing space'. Thus, not only does the representation of the various spaces depend upon the representation of space as that representation which these various spaces are in, but the representation of space is the representation of a unique particular. On this basis, Kant concludes that we take space to be 'a pure intuition' (A25/B39), a singular representation. This suggests, in turn, that the universal concept of space refers to a pure intuition: 'as far as space is concerned, an a priori intuition . . . lies at the basis of all concepts of space' (A25/B39).

In the fourth moment Kant continues his reflection on the basic fact about our usage - i.e. that we say we represent things in space. Since space is a pure intuition, it is a singular representation; and this, in light of the basic fact about our usage, suggests that space is a representation that contains other representations. But in what sense does space contain other representations? Is it importantly different from the way in which a concept may contain representations? This is Kant's concern in the fourth moment, where he distinguishes two ways in which a representation could contain other representations: 'under itself' versus 'within itself'. 
Now, it is true that one must think of every concept as a representation that is contained in an infinite multitude of different possible representations (as their common mark [Merkmal]), thus [a concept] contains these under itself. But no concept, as such, can be thought of as containing an infinite multitude of representations within itself. Yet this is how space is thought ... (B40)

Here Kant invokes a contrast between the way that concepts represent as opposed to the way that intuitions represent. A concept contains representations 'under' it. Concepts, in other words, are representations that govern other representations ('subsuming' them). ${ }^{26}$ What does a concept govern? It governs the representation of the particulars to which it applies. Judging that $x$ is an $\mathrm{F}$ is a way of representing $x$; the concept $F$ is the 'common mark' that infinitely many such judgements - representations - could share. ${ }^{27}$ In this sense, a concept is potentially contained in infinitely many representations, inasmuch as it may subsume infinitely many representations under itself. The intuition of space, however, does not contain representations under itself at all: intuition is a singular mode of representation, and hence is not happily thought of as applying to - subsuming, or governing our understanding of - other representations.

So far, we have just considered what it means to say that a concept contains representations 'under' it, and we have noted that there is no problem with the idea that a concept may contain infinitely many representations 'under itself'. Although the fourth moment seems to turn upon our granting that a concept cannot contain infinitely many representations 'within itself', ${ }^{28}$ the crucial point is arguably this: while concepts and intuitions may both contain representations 'within' themselves, they do so in different ways. In the third moment, Kant noted that while we can think of various spaces as parts of space, we do not think of them as constituent parts of space - parts out of which space is, as it were, built. A concept, however, does contain representations within itself in something like this sense. The concept buman does not subsume the concept mammal; it contains the concept within itself, as part of its content. What are the representations that a concept contains 'within' itself? The constituent concepts of its intension.

Throughout the Metaphysical Exposition, Kant repeatedly claims that the representation of space 'lies at the basis' of other representations: it 'lies at the basis' of the determination of particular spaces and the attribution of spatial predicates (first and second moments), and it 'lies at the basis' of any concept of space (third and fourth moments). 
Does this mean that the concept of space is derived from the pure intuition of space? Perhaps; but Kant cannot intend to tell a story about how we arrive at the concept of space from the pure intuition - at least not in the Transcendental Aesthetic. Such an issue is cut from the same cloth as Kant's difficult claim that the categories are not innate, but rather are 'originally acquired'. The account of how we acquire the concept of space would draw from explanatory resources that become available only later, in the Transcendental Deduction. ${ }^{29}$ Nevertheless, the Transcendental Aesthetic's analytic exposition of the concept of space should have the resources to show that we take the concept of space to refer to - and presumably also derive from - a pure intuition. Hence the final claim of the Metaphysical Exposition, at the close of the fourth moment: 'the original representation of space is a priori intuition' (B40).

I have presented the Metaphysical Exposition as an analytic exposition of the concept of space. We can refine and clarify our view of the Metaphysical Exposition if we pause to consider both how the concept of space is peculiar, as well as how the concept of space is just like any other concept. This should help us to avoid confusion about what the Metaphysical Exposition has revealed about the concept of space.

On my interpretation, this exposition is supposed to show that the concept of space refers to a pure intuition. Indeed, it is supposed to show that the concept of space refers to a unique particular: i.e. 'the one allencompassing space' (A25/B39). We might think that this result challenges the very idea of there being a concept of space at all: if concepts are general representations, how can there be a concept that refers to a unique particular? We can begin to address this by noting how the concept of space is a concept like any other: the content of a concept is articulated through its constituent concepts or intension. The concept of space presumably contains in its intension the concept representation, the concept intuition, the concept of the a priori, and so on. These constituent concepts determine that to which the concept of space may apply. However, it simply turns out that there is just one thing that meets all of the relevant criteria: space as pure intuition.

Saying this, however, brings a fresh difficulty to the fore. Earlier, I claimed that if it makes sense to say that there is a concept of space at all, then it should also make sense to say that particular spaces are appreciated as such through that concept: i.e. to recognize something as a particular space is to subsume it under the concept of space. How does this square with the Metaphysical Exposition's claim that the concept of space refers to a unique particular? If there is only 'the one 
all-encompassing space', perhaps it simply does not make sense to speak of particular spaces at all.

Here we must acknowledge a further peculiarity of the concept of space. The concept of space does not govern our understanding of particular spaces in quite the same way that the concept cup might govern our understanding of particular cups, or even as the concept virtue might govern our understanding of the concept of bravery. The representation of particular spaces, as Kant notes, 'rests solely on limitations' of the 'one all-encompassing space' (A25/B39). The concept of space refers to a unique particular: the pure intuition of space is a unique particular. Yet - and here I am simply reframing the previous point for emphasis - this unique particular is itself a representation. Moreover, this representation can admit infinitely many 'limitations' within it; indeed, the representation of particular spaces depends upon the introduction of such limitations into the representation of space. What this means, then, is that space must be understood to be a certain capacity for representing; it is a mode of representing. This may be acknowledged without losing sight of the idea that the concept of space refers to a unique particular. For there are properties of this unique particular. (Geometry provides the scientific account of its properties.) The properties of space, of this unique particular, are properties of an intuitional capacity for representing. Therefore, the referent of the concept of space is all of the following: a pure intuition, a unique particular, and a mode of representing. ${ }^{30}$

I have argued that the Metaphysical Expositions offer an analysis of the concept of space. I have taken this approach because it more faithfully acknowledges the rather gestural character of the text: the Metaphysical Exposition reads more like a collection of related assertions than it does like an argument (or set of arguments) that might apodictically demonstrate that space is an a priori intuition. How does this fare in the face of Kant's claim that the Aesthetic must 'not merely earn favor as a plausible hypothesis' but rather must 'be as certain and indubitable as can ever be demanded of a theory that may serve as an organon' (A46/B63)? Does it accord with the Aesthetic's aspiration to be a 'science of all a priori principles of sensibility' (A21/B35)? A science, by Kant's lights, is supposed to provide demonstrations establishing conclusions that we can be certain about. It does not seem that the Metaphysical Exposition has established any apodictic conclusions at all.

Neither the Metaphysical Exposition itself, nor the embellished version of the Metaphysical Exposition supplied by some commentators, 
can address what is arguably the crucial issue: namely whether these concepts refer to anything at all. I suggest that this is the crucial issue because the overarching aim of the Aesthetic is, after all, to establish that sensibility is a cognitive capacity. And in order to achieve this goal, it will be necessary first to show that there really are pure intuitions of space and time to which these concepts refer. Then it will be necessary to show that these pure intuitions play a necessary role in the cognition of objects. These issues are not addressed in the Metaphysical Expositions. The first issue is addressed in the Transcendental Expositions, and the second is addressed through the transcendental deduction of the concepts of space and time, which is presented in the sections of commentary that follow the Expositions. Only then do we have what could arguably be admitted as an apodictic result.

Thus, the Metaphysical Expositions have left us expecting, or hoping, that the Transcendental Exposition will show that space must be as the Metaphysical Exposition presented it. Let us now turn to the Transcendental Exposition to see if these expectations are met.

\section{5.}

As I suggested before, we can distinguish the task of concept analysis, as the presentation of what is thought in a given concept, from the demonstration that the concept in question refers to something real. We might, in typical contexts, think of the latter task as establishing the 'objective validity' of the concept.

But the case of the concepts of space and time is not typical. What we find in the Aesthetic is first, an account of the legitimacy of these concepts (in the Transcendental Exposition), followed by an account of their objective validity (in their 'transcendental deduction'). ${ }^{31}$ So, when we present the concepts of space and time in the Metaphysical Expositions, we find that we take these concepts to refer to pure intuitions: this is reflected in our usage of these concepts. But we still face a question about whether these concepts refer to something that really exists: our usage of these concepts reflects a commitment to the idea that space and time are pure intuitions, but is that commitment legitimate? After all, our concepts of space and time could be fraudulent or confused expressing our commitment to something that is not real in any way at all. The Transcendental Expositions show that the concepts of space and time are not fraudulent, because they have a real referent (namely, space and time as pure intuitions). 
Of course, the claim that the concepts of space and time refer to something 'real' needs special handling, since (e.g.) the concept of space is importantly different from the concept of a theoretical entity, and also from a concept like chair. While the account of the legitimacy of a concept involves an account of the reality of its referent, the reality of the pure intuitions of space and time needs to be understood within the general context of transcendental idealism, as Kant explains in the sections of commentary that follow the Expositions. It is only in these sections of commentary that we find Kant's account of the objective validity of the concepts of space and time; there we find the transcendental deduction of these concepts - an account of how they apply, with necessity and universality, to objects of our cognition.

For now, let us focus our attention on the Transcendental Expositions. A transcendental exposition, Kant explains, is

the explanation of a concept, as a principle from which the possibility of other synthetic a priori cognition can be understood. To this end it is required 1) that the cognitions really do flow from the given concept, 2) that these cognitions are only possible under the presupposition of a given way of explaining this concept. (B40)

In overview, the Transcendental Exposition of space proceeds as follows. Kant begins by invoking geometry's status as a 'science' that 'determines the properties of space synthetically and yet a priori' (B40). Geometry is concerned with the properties of space; this knowledge is not derived analytically from mere concepts, but rather through the practice of reasoning with diagrams (the construction of concepts). Hence even though we speak of a concept of space, '[s]pace must originally be intuition' (B40). Moreover, since geometry yields only apodictic claims, Kant maintains that space must be 'pure, not empirical, intuition' (B41).

On my reading, the argumentative burden of the Transcendental Exposition is to show that the concept of space - as unpacked in the Metaphysical Exposition - refers to something that really exists, namely space as a pure intuition. Let me begin by defending this general view of the Transcendental Exposition's task. For it might seem that my interpretation fails to give due weight to the fact that the Transcendental Exposition is, after all, an exposition - which, as we have seen, means that it should present the content of a concept (A23/B38). How does showing that space exists as pure intuition continue the project of expositing the content of the concept of space? 
The Metaphysical Exposition reveals our commitment to the idea that the concept of space refers to a pure intuition; and, as I reflected on this result above (in $\mathbb{S} 4$ ), this means in turn that the concept of space refers to something in our subjective makeup, a mode of representing. The Transcendental Exposition shows that there really is such an aspect of our subjective makeup. In arriving at this result, the Transcendental Exposition appeals to the existence of geometry: we admit as given that we legitimately make cognitive claims of a certain sort (we determine 'the properties of space synthetically and yet a priori', B40). Space, as pure intuition, is the object of such cognition. With geometry presupposed - at least as a science of space, if not yet as a science of nature ${ }^{32}$ - it follows that space, as pure intuition, really exists. In this way, the Transcendental Exposition reveals something new about what belongs to the concept of space: namely that the pure intuition to which this concept refers is a source of synthetic a priori cognition. While the Metaphysical Exposition is an analytic exposition (unpacking the content of the concept of space), the Transcendental Exposition is a synthetic exposition: it contributes to the presentation of the content of the concept of space, but it does so 'synthetically' by making an existence claim. ${ }^{33}$

We will gain a clearer understanding of this last point, and better appreciate both the argument and result of the Transcendental Exposition, if we confront a methodological objection that is often pressed against this text. The worry has to do with Kant's appeal to geometry in the Transcendental Exposition. ${ }^{34}$ When Kant contrasts the 'synthetic' method of the Critique with the 'analytic' method of the Prolegomena, he glosses the distinction by insisting that the Critique is 'robbed of all help from other sciences' (4:275), and 'lays nothing as given for its basis except reason itself' (4: 274). By contrast, the Prolegomena assumes the actuality of certain bodies of synthetic a priori cognition, and argues regressively to the conditions of their possibility. The worry is that the Transcendental Exposition starts to look a lot like the regressive argument of the first part of the Prolegomena. ${ }^{35}$

I do not think that this methodological worry about the Transcendental Exposition is tangential to the concerns of this paper, although it will take a little time to bring out its relevance to our task here: namely, to gain a clearer view of the philosophical resources of the Transcendental Aesthetic in order to come to terms with Kant's retrospective identification of a transcendental deduction of the concepts of space and time. In order to work through the relevant issues, we must begin by taking a closer look at the argument of the Transcendental Exposition. 
Kant draws two inferences in the Transcendental Exposition. The first stems from geometry's status as a body of synthetic a priori claims; since this cognition of the determinacy of space does not proceed from the analysis of concepts alone, it relies upon some intuition (space). The second inference proceeds from the fact that geometry's propositions are 'one and all apodictic, i.e. bound up with the consciousness of their necessity' (B41); from this Kant seems to infer that space must be a pure intuition. Here Kant appears to draw the following inference: since geometry yields only apodictic cognition, therefore the object of this cognition - space itself - must be a pure, rather than an empirical, intuition.

This second inference looks problematic, as it would seem to meet with a counterexample in the case of 'pure natural science' - a science which Kant takes to be apodictic. If pure natural science is concerned with nature, then it would seem to pertain to what can only be given in experience, i.e. empirically. Thus we seem to have a counterexample blocking Kant's inference from the apodictic status of geometry to the conclusion that its object (space) must be given a priori (i.e. be pure intuition). In order to address this issue, we will need to consider briefly Kant's conception of pure natural science, and how it differs from empirical (or experimental) natural science.

Pure natural science is not directly concerned with material naturei.e. the actuality of nature given in sense experience. If pure natural science has an object, it is the very idea of 'a nature in general' (B165). This idea of a nature in general is articulated in terms of the battery of synthetic a priori propositions that Kant calls the principles of pure understanding; these principles express 'the conformity to law of appearances in space and time' (B165). These are the principles by which nature, as the sum total of appearances, can be determined a priori to a certain formal unity - i.e. possible experience. Pure natural science does not yield cognitive claims about the actuality of material nature. Experimental natural science offers cognitive claims about the actuality of material nature. And while it posits laws of nature - propositions that purport to express what necessarily happens, rather than what seems to happen for the most part - these laws are contingent in the following sense. The principles of pure natural science might have been realized in a world that had a different concrete actuality: they could have been realized in a world without electrons, osmosis, or gravitational attraction. This is a point that Kant reinforces in the Critique of Judgement's Introduction: the principles of pure understanding leave much undeter- 
mined in empirical laws of nature. ${ }^{36}$ There are certain contingent facts about the world in which we find ourselves. These facts figure in the content of these empirical laws; this is what is left undetermined by the principles of the pure understanding.

But how does this bear on the Transcendental Exposition of space? Ultimately, it teaches us how to appreciate Kant's appeal to geometry; it does this by indicating why Kant's inference - from the apodictic status of cognition to the a priori status of its object - may be legitimate after all. Although laws of nature are posited in experimental natural science, this does not entail that there might not have been other empirical laws. Therefore, the claims of empirical natural science are not apodictic in the strict sense: they are not 'bound up with the consciousness of their necessity'. However, suppose that we accept Kant's arguments in the Critique's Transcendental Analytic. It would follow that the propositions of pure natural science - spelled out as the battery of principles of the pure understanding - are apodictic: in so far as we recognize these principles at all, we in turn recognize their necessity. That apodictic cognition is transcendental cognition concerned with the essential character of our cognitive capacity. By these lights, then, mathematics offers apodictic cognition because it pertains to the nature of representations fundamental to our cognitive capacity, and does not pertain directly to the material actuality of nature.

With this, we can return to the methodological problem noted above. The Transcendental Exposition's appeal to geometry is legitimate, I am suggesting, if it simply appeals to the point that geometry concerns the a priori determinacy of the representation of space. For the particular determinacy of space is established without regard to the material actuality of nature. As Kant explains later on in the Aesthetic, if the intuition on which one had to 'rely' in order to recognize that two straight lines cannot enclose a space were empirical, then the resulting proposition would not be universally valid and apodictic as we know the claims of geometry to be (A47-8/B64-5). Empirical intuition involves sensation; it is therefore dependent, at least in part, on the actuality of material nature. For Kant, then, the apodictic status of geometry's claims can be accounted for only if space is pure intuition. Hence Kant may conclude that 'our explanation' of the concept of space - the one provided in the Metaphysical Exposition - 'alone makes the possibility of geometry . . . comprehensible’ (B41). Space must really exist as a pure intuition. 
What I mean to suggest, then, is that the Transcendental Exposition invokes geometry merely as a science of space - and not as a science of nature. If this is correct, then the Transcendental Exposition does not flout the methodological restriction on the Critique for the following reason: the Critique cannot draw upon any science of material nature, for then its claims would not be apodictic in the strict sense that Kant invokes in the Transcendental Exposition. Geometry is apodictic (its claims are 'bound up with the consciousness of their necessity') and any apodictic discipline is, I am suggesting, fundamentally a study of the nature of reason itself. Thus Kant may invoke geometry without thereby drawing on something other than 'reason itself'. ${ }^{37}$

Of course, Kant's considered view is that mathematics is a science of nature: later, he remarks that mathematics does not yield cognition except insofar as it is applicable to appearances $(\$ 22, \mathrm{~B} 146-8)$. But this only shows that, for Kant, the mere idea of a mathematical science does not - by itself - entail anything about cognition of material nature. The Transcendental Exposition lies well upstream of any account of the necessary applicability of mathematics to appearances; only this could show mathematics to be a science of nature. Geometry may be admitted as given at the outset of the Transcendental Exposition - but merely as a science of space, and not as a science of nature. Hence the apodictic status of geometry can be drawn upon independently of the question about geometry's application to appearances. For the purposes of the Transcendental Exposition, geometry is concerned merely with the necessary determinations of space as pure intuition, a mode of representing.

Let me recapitulate the main points of my interpretation of the Transcendental Aesthetic's project of exposition. 'Exposition' refers to the presentation of the content of a concept. The task of the Metaphysical Exposition is concept analysis. The Metaphysical Expositions simply reveal our commitment to the idea that space and time are pure intuitions. They cannot establish that we are right to think of space and time in this way: after all, Kant recognizes that many natural philosophers get along with inadequate conceptions of space and time (A39-41/B56-58). The Transcendental Expositions show the concepts of space and time (as exposited in the Metaphysical Expositions) to be legitimate, by establishing the reality of their referent. This furthers the task of 'exposition' (i.e. presenting what belongs to a given concept), because we recognize something further about the concept: the pure intuition to which it refers is also a source of synthetic a priori cognition. 
This is a 'synthetic' exposition because the claim in question draws upon the recognition this pure intuition really exists, as an element of our representational makeup.

The transcendental deduction of the concepts of space and time is made explicit in the sections of commentary that follow the Expositions. Kant's express task in those sections is to show that our view of the reality of space and time must be appreciated within the context of transcendental idealism. Where, in this commentary, is the transcendental deduction of the concepts of space and time? I shall consider those issues now.

\section{6.}

Nowhere in the text of the Aesthetic itself does Kant refer to any 'transcendental deduction' of 'the concepts of space and time'; he mentions it only later, in the run-up to the Transcendental Deduction of the categories (\$13, A87/B119-20). This deduction is supposed to have 'traced' these concepts 'to their sources' and 'explained and determined their a priori objective validity’ (A87/B119-20). A transcendental deduction is an account of the objective validity of an a priori concept. On the basis of my account, it may seem that the Transcendental Expositions provide that transcendental deduction. For I argued that while the Metaphysical Expositions reveal our commitment to the idea that space and time are pure intuitions, the Transcendental Expositions show that there really are such pure intuitions (to which the concepts of space and time refer). But as I mentioned above, Kant addresses the legitimacy of the concepts of space and time separately from their objective validity. For it is one thing to establish that, say, space really exists as a pure intuition (and therefore the account of the concept of space in the Metaphysical Exposition must be endorsed), and something else to account for the necessary universal applicability of the concept of space to external objects. The Transcendental Exposition addresses the legitimacy of these concepts, whereas the transcendental deduction addresses their a priori objective validity.

In the Prolegomena, Kant discusses the task of a transcendental deduction of space and time in just these terms. The transcendental deduction, Kant explains, promises to remove the following threat: namely, that the concept of space, and hence mathematics itself, would have no necessary application to appearances $(4: 287,292)$. This deduction should show 'the space of the geometer' to be no 'mere invention' 
that one 'would credit with no objective validity' (4: 287). Without this transcendental deduction, the claims of mathematics could very well be 'determinations of a mere creation of our poetic imagination, and thus could not reliably be related to actual objects' (4: 287). So, while the Transcendental Exposition establishes that there really exists something to which the concept of space, as exposited in the Metaphysical Exposition, refers - namely space as a pure intuition - it does not explicitly address the applicability of the concept of space to objects in the world outside of us. ${ }^{38}$

The transcendental deduction of the concepts of space and time makes explicit the upshot of the expositions of space and time: it is their direct consequence. The expositions show that the concepts of space and time legitimately refer to pure intuitions of space and time. And since space and time are pure intuitions constitutive of our receptivity, the concepts of space and time - simply by referring to these pure intuitions - are necessarily valid of all appearances. Hence these concepts are necessarily applicable to any possible object of experience. This simple inference is the transcendental deduction of the concepts of space and time. But the significance of this transcendental deduction can be appreciated only in light of the broader aims of the Critique.

\section{7.}

According to Kant, we are in no position to appreciate the need for a transcendental deduction of the concept of space (he does not mention time) until we face the problem of establishing the objective validity of the categories. For the discovery of categories, Kant maintains, engenders a certain confusion about the concept of space that makes its transcendental deduction as imperative as any.

Yet with the pure concepts of the understanding [i.e. the categories] begins the unavoidable requirement to seek a transcendental deduction not only of them, but also of space; for ... these [pure] concepts [of the understanding] ... refer to objects universally, apart from all conditions of sensibility. And, since they are not grounded on experience ... they arouse suspicion on account of the objective validity and limits of their employment, but they also make the concept of space ambiguous, for they have a tendency to use it even beyond the conditions of sensible intuition, on account of which a transcendental deduction of it was also needed above. (A88/B120-1) 
The categories are concepts that purport to stem from the nature of the intellect alone; at the same time, they purport to be applicable to objects a priori. The battery of such concepts, Kant here suggests, presents at least the idea of an intelligible world - a world determinable by these concepts alone. Once such a world is invoked, we soon find ourselves thinking, for example, of causal interactions between substances in such a world. But we find that we cannot help but to think of these substances interacting from various locations in space; so if we take ourselves to be able to make cognitive determinations about the objects of such a world, then we inevitably involve the concept of space. This renders 'the concept of space ambiguous', since we are involving it in claims about intelligibilia, when it rightfully pertains only to sensibilia.

The inevitability just pointed to stems from a contingent fact about us: that human sensibility is constituted by space and time. In this respect, the intuitions of space and time have a crucially different status, in Kant's system, from the categories. Since the categories are derived from functions of judgement presented by pure general logic, Kant supposes that any discursive understanding is constituted by such concepts: for there are simply no other functions that preserve the coherence of thought, and hence there can be no other concepts that could be constitutive of an understanding. With the invocation of such concepts comes the idea of an intelligible world - an idea that is presumptive and fraudulent as soon as it is treated as anything more than a mere idea.

We can see, then, that two distinct points emerge from the Expositions, both resting on the single idea that space and time are constitutive of our sensibility. One is the transcendental deduction, sensu stricto: because these concepts refer to pure intuitions that are constitutive of our sensibility, it follows that these concepts are necessarily applicable to all appearances that could figure in any possible cognition. The second point specially accommodates the point that space and time are constitutive of our sensibility: the concepts that refer to these pure intuitions are applicable only to appearances.

We can also now appreciate the apodictic result that the Aesthetic is supposed to provide for the subsequent arguments of the Critique: it is supposed to clarify the concepts of space and time so that they will no longer be employed in an 'ambiguous' manner. This, in turn, is supposed to establish a necessary limitation on the employment of the categories. For unlike the categories, Kant explains, the concepts of space and time 'determine their own bounds' (A39/B56). They are selflimiting simply because they refer to the intuitions of space and time: 
intuition is the mode of representation that expresses the receptivity of sensibility. The concepts of space and time are like the categories in being pure, and not empirical; but they are importantly unlike the categories in that the presentation of these concepts does not invoke any notion of a noumenal world. We appreciate that point only through the exposition of these concepts, which establishes that they refer to pure intuitions.

I have delayed directing our attention to the passages that actually contain the transcendental deduction of the concepts of space and time. This is because we can hardly make out this transcendental deduction until we appreciate why it is required; and our appreciation of why this transcendental deduction is required can only be rendered vivid when the perennial threat of dogmatic metaphysics is appreciated in light of the categories' status as concepts that stem from the 'nature of the understanding alone'. Hence Kant's merely retrospective identification of the transcendental deduction of the concepts of space and time, in the preamble to the transcendental deduction of the categories $(\mathbb{S 1 3})$. We can now turn to the passage that contains the transcendental deduction of the concept of space:

Because we cannot make the particular conditions of sensibility into conditions of the possibility of things, but rather only of their appearances, we can indeed say that space encompasses all things that may appear to us externally, but not all things in themselves, be they intuited or not, or by whatever subject they may be intuited ... If we add the limitation of a judgement to the subject concept, then the judgement is unconditionally valid. The proposition, 'all things are next to one another in space', is valid under the limitation: if these things are taken to be objects of our sensible intuition. If I add here the condition to the concept and say: 'all things, as outer appearances, are next to one another in space', then this rule is valid universally and without limitation. $(\mathrm{A} 27 / \mathrm{B} 43)^{39}$

The passage captures both the transcendental deduction itself, and its significance for Kant's reconception of metaphysics within the framework of transcendental idealism. The concept of space is necessarily applicable to all outer appearances that could figure in any possible cognition. And yet, our account of the universal objective validity of the concept of space cannot abstract from the 'human standpoint' (A26) B42). Thus we are reminded that the concept of space is applicable only to outer appearances. 
The Aesthetic's transcendental deduction provides only a minimal account of how the concepts of space and time must be valid of objects a priori: namely because these concepts refer to pure intuitions that are constitutive of our sensibility. Despite this minimal account, the Aesthetic yields a result for the transcendental deduction of the categories. That result is the transcendental deduction of the concepts of space and time, which explains that these concepts are self-limiting. Since these concepts refer to pure intuitions, and these pure intuitions are actualizations of our receptive capacity, these concepts necessarily apply to any object of reason's theoretical cognition. In this way, the Aesthetic introduces a necessary limitation on any valid employment of the categories - a result that proves crucial for the subsequent vindication of the claim of reason, at least as Kant conceived of it. ${ }^{40}$

\section{Notes}

1 In this paper, I use the terms 'cognition' and 'knowledge' interchangeably although I usually translate Kant's Erkenntnis with 'cognition'. References to Kant's works, with the exception of the Critique of Pure Reason, refer to the volume and page of the German Academy of Sciences edition (Gesammelte Schriften, ed. Königliche Preußische Akademie der Wissenschaften, later the Deutsche Akademie der Wissenschaften zu Berlin. 29 volumes. Berlin: Walter de Gruyter [and predecessors], 1902-.) References to the Critique of Pure Reason are cited according to the pagination of the first (A) and second (B) editions. Translations are my own (unless otherwise noted), but I consult the commonly used English translations.

2 This characterization of the categories draws from Kant's account of the difference between intellectual, empirical, and arbitrary concepts in the Jäsche Logic (9: 94).

3 Titles of any section of the Critique are given, often in abbreviated form, with the standard capitalization for titles; without such capitalization, the phrase instead refers to the general sort of argument or account in question. For example, Kant's reference to a 'transcendental deduction of the concepts of space and time' refers to no titled section of the book, and receives no capitals; the Transcendental Deduction of the Pure Concepts of the Understanding does.

4 Commentators tend to pass over Kant's remark about a transcendental deduction of space and time altogether; those who do address it tend to do so obliquely, or in footnotes - under the radar, as it were. And we find a wide range of views on the matter. Lorne Falkenstein says that this deduction is 
to be found in the Transcendental Aesthetic's Metaphysical Expositions of space and time; see Kant's Intuitionism: A Commentary on the Transcendental Aesthetic (Toronto: University of Toronto Press, 1995), pp. 394-5, n. 12. Daniel Warren is non-committal: he first implies that this deduction would be found in the Transcendental Aesthetic's Transcendental Expositions of space and time which follow the Metaphysical Expositions, maintaining that the objective validity of space and time cannot be addressed until after the Metaphysical Expositions; see 'Kant and the Apriority of Space', Philosophical Review, 107 (1998), 179-224, p. 222, n. 57 and pp. 222-4. But in the final sentence of his paper, he seems to imply that this deduction might instead be achieved through the Transcendental Deduction of the categories (p. 224). Sadik Al-Azm hints that the transcendental deduction of space and time requires the 'synthetic approach' of the Transcendental Deduction of the categories, and not the 'analytical' approach of the Aesthetic: 'In this [synthetic approach] lies their transcendental justification'; see Kant's Theory of Time (New York: Philosophical Library, 1967), p. 35 .

5 Karl Ameriks supposes that the transcendental deduction of space and time is the Aesthetic's Transcendental Exposition, and then goes on to treat Kant's remarks about 'transcendental exposition' as a guide to understanding the transcendental deduction of the categories; see 'Kant's Transcendental Deduction as a Regressive Argument', Kant Studien, 19 (1978), 27387 , pp. $274 \mathrm{ff}$.

6 It is to be expected of a project as systematically driven as the Critique that our grasp of one part of the book should depend upon our grasp of another. Indeed, in so far as the Critique is truly a system, we should expect this to work in more than one direction: not only should an earlier part of the book provide a result that allows for a later argument to go through, at the same time the result of a later argument could mandate a return to an earlier part of the book so that we may see it in a newly corrected light. Much of the recent work on the relation between the Aesthetic and the Deduction is retrospective in this way, arguing that the Deduction reveals the Aesthetic to be a provisional text. See Béatrice Longuenesse, Kant and the Capacity to Judge (Princeton: Princeton University Press, 1998), esp. chapter 8; Wayne Waxman, Kant's Model of the Mind (Oxford: Oxford University Press, 1991), esp. chapter 2; and, looking further back, Sadik Al-Azm, Kant's Theory of Time, part II. For an example of recent commentary resisting this trend, see Lorne Falkenstein, Kant's Intuitionism, especially chapters 1 and 2.

The view of the Aesthetic as a provisional text is typically adopted on the basis of the Deduction's concluding argument regarding a spontaneous capacity of the mind 'to determine sensibility a priori' ( $\$ 24$ B152; cf. $\$ 26$ B160n.) - a capacity expressed in what Kant refers to as 'figurative synthesis'. As Longuenesse argues, the Aesthetic is provisional because Kant 
ultimately 'wants to reveal in these forms [of intuition, i.e. space and time] the manifestation of an activity that only the Transcendental Deduction of the Categories can make explicit' (Kant and the Capacity to Judge, pp. 211 and 213). In other words, the Aesthetic had to talk about things that it lacked the resources to account for; hence a 'retrospective clarification' of the Aesthetic is in order once those resources are in hand (Kant and the Capacity to Judge, p. 217; see also Waxman, Kant's Model of the Mind, p. 80).

7 Could the Critique have been organized differently, so that the account of sensibility followed the account of the understanding? Kant addresses this question, briefly, in an unsent draft of a letter to J. H. Tieftrunk. There he says only that the order of exposition actually found in the Critique is certainly more 'natural' (13: 463), but does not maintain that it is required. But in the Critique itself, Kant suggests that the order of exposition - the Aesthetic first - is indeed required (A16/B30; see also Critique of Practical Reason, 5: 89-90).

8 By 'hylomorphism thesis', I refer to Kant's claim that a distinction can be drawn between the 'matter' and 'form' of intuition. In the Aesthetic, Kant goes on to explain their relation in the following way. Matter is dependent upon form: sensation cannot figure as matter for empirical intuition apart from the formal (spatio-temporal) conditions identified in the Aesthetic. Yet form is independent of matter, inasmuch as we can represent 'pure space' and 'pure time' at all.

9 This may be the place to mention an interpretative strategy of Lorne Falkenstein, who generally aims to take the Aesthetic on its own terms resisting the trend to read the Aesthetic as a provisional text in light of the Transcendental Deduction's doctrine of figurative synthesis (on this general issue, see note 6 above; in Falkenstein's text see, e.g. p. 383, n. 31). Despite this, Falkenstein is prone to read the Critique backwards, relying on later developments in order to fill the gaps of the arguments he sees Kant as making (or needing to make) in the Aesthetic. For example, Falkenstein remarks that, at the end of the Aesthetic's Metaphysical Expositions, Kant has not yet 'presented an argument that could demonstrate that space and time could not have originated from any sort of intellectual process whatsoever' - instead he has only shown that 'certain intellectual processes are inadequate to do this job' (p. 242). In order to fill the gaps of what he takes to be Kant's argument, Falkenstein points to the Transcendental Analytic's putatively complete table of four types of synthesis (pp. 242-3); he then argues that 'none of these four . . types of synthesis could plausibly be supposed to originally generate a representation of space or time out of intuitions that are originally aspatiotemporal' (p. 243). Whatever the philosophical insight of Falkenstein's account, it is distracting if our aim is to interpret the Aesthetic in a manner that is consonant with its own philosophical resources. (For another passage that raises similar concerns, see Kant's Intuitionism, p. 73.) 
10 Practical cognition does not merely determine its object, but also makes it actual $(\mathrm{Bix}-\mathrm{x})$.

11 The division into 'metaphysical' and 'transcendental' exposition is made explicit only in the second edition. I will be dealing with the second-edition text.

12 See e.g. Henry Allison, Kant's Transcendental Idealism, revised and enlarged edition (New Haven and London: Yale University Press, 2004), pp. 465-6, n. 5).

13 Kant, Falkenstein remarks, 'needs simply to prove that our concepts of space and time are concepts of the form of intuition rather than the matter of intuition, of the objects of appearance, or of the functions of intellectual synthesis. As a matter of fact, this is what Kant does' (Kant's Intuitionism, p. 150).

14 I dispute the details of Falkenstein's account on methodological grounds especially (see note 9 above).

15 As space and time are presented as concepts that admit of such exposition, they are, presumably, concepts that are 'given a priori'. In the Jäsche Logic, Kant distinguishes between 'given' and 'made' concepts: the content of given concepts is revealed analytically, while the content of made concepts is established synthetically. Kant also refers to the 'exposition (of appearances)' as the explanation of the content of concepts made from empirical synthesis ( $\$ 102$, 9: 141$)$.

16 On definition, and why philosophy cannot offer definition in the strict sense (while mathematics can) see A730/B758; and Jäsche Logic \$S100-102, 9: 141. See also Kant's caveat that we should not expect to find definitions in the Critique: the work must provide a 'complete enumeration of the fundamental concepts which comprise the pure cognition under consideration', but it will not provide a 'complete analysis of these concepts' (A13/B27).

17 The Jäsche Logic uses the German Erörterung, whereas the Doctrine of Method uses the Latinate Exposition. However, the Jäsche Logic glosses Erörterung with the Latin exposition (9: 142), suggesting that remarks about exposition (Exposition) in the Doctrine of Method offer interpretative guidance regarding the expositions (Erörterungen) of space and time in the Aesthetic.

18 Here I am employing a somewhat limited notion of conceptual content - a notion of content that abstracts from questions about cognitive significance. In this respect, we can speak of the content of the concept phlogiston, even if this concept is not objectively valid or has no genuine cognitive significance. On this limited conception, the content of a concept can brought out by reflecting upon our usage of the concept, and taking note of the relevant entailment relations; it is still a further question to consider whether the concept in question has genuine cognitive significance or objective validity. A cognitively void concept could, in this restricted sense, still have content. 
19 Since the Transcendental Expositions address an existence claim - namely that the concepts of space and time, as exposited in the Metaphysical Expositions, have a real referent - they can be thought of as the 'synthetic' complement to the mere concept analysis of the Metaphysical Expositions. While most commentators treat the Transcendental Expositions as an analytic 'argument from geometry', Lisa Shabel argues that this is mistaken; see 'Kant's "Argument from Geometry"', Journal of the History of Philosophy, 42 (2004), 195-215. Her view of the synthetic burden of the Transcendental Exposition differs significantly from my own, however. I assess this in note 33 below.

20 See note 9 above.

21 Warren, 'Kant and the Apriority of Space', $\$ 5$.

22 Warren himself does not make much of the idea that the Metaphysical Expositions are concept analysis, and he remains somewhat non-committal about the repeated references to the concepts of space and time in the Aesthetic ('Kant and the Apriority of Space', pp. 219-20, n. 52).

23 From a methodological perspective, the reconstructive approach that commentators have taken toward the Metaphysical Expositions is often problematic. Warren, for example, reconstructs only what he takes to be the 'first apriority argument'; this leaves us wondering about its role in the account as a whole - how does it relate to the other three 'a priority arguments' that Warren suggests should be found in the Metaphysical Exposition? Why do we need four apriority arguments - is one not sufficient?

24 Many commentators follow Henry Allison in seeing the division of labour in the Metaphysical Exposition in the following way: the first two moments provide two distinct arguments in favor of the apriority of the representation of space, while the second two moments provide two distinct arguments in favor of claim that space is an intuition rather than a concept (see Kant's Transcendental Idealism, pp. 99-112; for a recent endorsement of this view, see Shabel, 'Kant's "Argument from Geometry"', pp. 198-9). The moments do indeed seem to come in pairs, with the first pair arguably emphasizing the apriority theme, and the second pair arguably emphasizing the intuitionality theme. Nevertheless, emphasizing one issue over the other is not the same as disentangling the two and treating each in isolation from the other, so that distinct arguments for the apriority and intuition theses are advanced (or supplied by commentators). Take, for example, the second moment: even though it arguably emphasizes the apriority issue, it still has the intuition issue in play. For there Kant says that space is not to be regarded 'as a determination dependent upon appearances' (A24/B39). Inasmuch as the notion of 'determination' (Bestimmung) is generally associated with theories of judgement and hence with concepts, Kant seems to be working toward the claim that space is not a concept at the same time that he is working toward the claim that space is a priori. 
At any rate, I am advocating a more holistic treatment of the Metaphysical Exposition than is standard. I have come to this interpretative position in large part because the text does not bear out the standard interpretative claim that there are four distinct, but interrelated, arguments. We find a far better characterization of what is actually there on the page of the Metaphysical Exposition in Kant's remarks regarding the analytic exposition of given concepts. In the Critique, he emphasizes that such exposition is merely 'valid to a certain degree' (A729/B757). And in the preCritical Prize Essay, Kant says that analytic exposition merely brings out what we 'notice' about the content of the concept - where these claims may be 'elucidated' but 'can never be proven' (2: 281). The Metaphysical Exposition better resembles a collective set of remarks offering gradual clarification and elucidation of the content of the concept of space, than it does a set of four apodictic demonstrations.

25 Speaking roughly, we might say that one rhapsodic blotch is 'bigger than' another, or 'to the left of' another, or even positioned at a certain relative distance from another (e.g. "blotch $a$ stands at a distance of half the width of blotch $a$ to blotch $b^{\prime}$ ). But to be precise we should not refer to these as spatial properties, but rather as properties analogous to spatial properties; this is because rhapsodic blotches are not in space at all.

26 My interpretation here does not draw upon anything other than the fundamental distinction Kant draws between intuition and concept as modes of representation; this distinction is already in place from the beginning of the Aesthetic (\$1 A19/B33).

27 A judgement is a representation ('the representation of a representation', A68/B93).

28 The fourth moment turns on the point that we cannot conceive of a concept's containing an 'infinite multitude' of concepts within its intension. But this is not a self-evident claim, even though Kant treats it as one. For it is not hard to imagine a theory of concepts that would not find any incoherence in this idea. Such a theory might say of the concept book that the predicate is not a member of parliament belongs to its intension; and so does the predicate is not the number 2 , along with much else. Such a theory could countenance the possibility of a concept's containing infinitely many representations within its intension. Kant, however, seems to be considering the nature of concepts, at least with respect to their intension, quite differently. He is evidently supposing that certain considerations of relevance factor into what we can plausibly take the intension of a concept to be $-\mathrm{a}$ great many negative predicates will simply not be relevant. Unfortunately, Kant does not argue the point; and the incoherence of a concept's containing infinitely many predicates in its intension is not self-evident.

29 In $\$ 26$ of the Transcendental Deduction, Kant says that it is through figurative synthesis that 'all concepts of space and time first become possible' (B161n.). Kant's remark indicates that we should not expect the Aesthetic to 
provide an account of how we acquire the concepts of space and time, since such an account would need to draw upon resources that presumably only become available in the Deduction. Cf. 'Über eine Entdeckung' (8: 221-3), where Kant indicates that not only are the categories 'originally acquired' but also the pure intuitions of space and time. The issue of original acquisition is central to Waxman, Kant's Model of the Mind (pp. 44-7, and chapter 3), and also figures prominently in Longuenesse, Kant and the Capacity to Judge (chapter 8, esp. p. 222; and pp. 252ff.).

30 Some clarification of this claim that the concept of space refers to 'all of the following: a pure intuition, a unique particular, and a mode of representing' is in order, as an anonymous referee has suggested. It makes sense to say that (e.g.) there are distances between various conceivable points in space if we take space to be either a pure intuition or a unique particular. But is it not rather strained to suppose that there are distances between various conceivable points in space considered as 'a certain capacity for representing' or a 'mode of representing'? However, there is no need to attribute distances between various conceivable points to the capacity for a priori intuition. Rather, there would only be such distances in any representation of space, i.e. in any representation that results from the exercise of this capacity. The capacity in question is constitutionally connected to the representation of space as pure intuition. More generally, saying that the concept of space refers to a capacity for intuition entails that spatial properties apply to things as they are represented through the exercise of this capacity.

31 Kant does not refer to an account of the 'legitimacy' of these concepts - that is my term; but he does, of course, refer to the account of their objective validity, through their transcendental deduction. The account of the legitimacy of the concepts of space and time differs from the account of their objective validity in the following way: the account of their legitimacy just shows that these concepts have a real referent (space and time as pure intuitions), while the account of their objective validity addresses their necessary applicability to objects that can only be given in experience. For more on this, see $\$ \$ \$ 6-7$ below.

32 The importance of this point will be brought out below.

33 In denying that the Transcendental Exposition offers a regressive 'argument from geometry', Shabel suggests that its task is 'synthetic' (see pp. 195-6 and passim). Although I agree that the argumentative burden of the Transcendental Exposition is 'synthetic', I find serious problems with her account.

Shabel explains the relation between the Metaphysical Exposition and the Transcendental Exposition in the following way: the Metaphysical Exposition issues a 'background claim that space is a pure intuition', leading Kant to ask, in the Transcendental Exposition, 'how does our representation of space manage to afford us those cognitions that are the unique domain of the science of geometry? His question is not whether it does so, but how' (p. 203). While I acknowledge that Kant's overarching question in the 
Critique is of the latter sort, it must be recognized that the Transcendental Aesthetic does not possess the explanatory resources to provide any account of how synthetic a priori judging is possible, or even how some particular species of it is possible (e.g. geometry). In the Critique, Kant proceeds with the general question about the possibility of synthetic a priori judging (B19-22); he does not attempt to address - piecemeal - separate questions about the possibility of pure mathematics, of pure natural science, and of metaphysics (as he does in the Prolegomena). The general question about the possibility of synthetic a priori cognition, or judging, only begins to be addressed in the Transcendental Deduction, since the account of its possibility rests on the establishment of the principle of the synthetic unity of apperception. In short: the Aesthetic's Transcendental Exposition does not possess the explanatory resources to address the question that Shabel attributes to it -i.e. a question about how the science of geometry is possible.

Moreover, Shabel does not give adequate attention to the difference in modality between the conclusions of the Metaphysical Exposition versus the Transcendental Exposition. On Shabel's view, Kant 'takes himself already to have shown that space is a pure intuition' in the Metaphysical Exposition (p. 202) - she sees this as a concrete result on which Kant then builds a 'philosophical bridge ... to his transcendental idealism' (p. 196), with Kant's philosophy of mathematics serving as the relevant bridge. However, we should consider the contrast between the Metaphysical Exposition's claim that 'the original representation of space is a priori intuition' (B40, my emphasis on the copula), and the Transcendental Exposition claims that space 'must originally be intuition' (B41). On my reading, this difference can be explained: the Metaphysical Exposition is analytic, laying bare merely what we actually think in a given concept, whereas the Transcendental Exposition is synthetic, showing that there really is something to which this concept refers - space as pure intuition. The Transcendental Exposition shows that space must really be as exposited in the Metaphysical Exposition.

34 The Transcendental Exposition of time relies, in a similar fashion, on what Kant refers to as the 'general theory of motion [allgemeine Bewegungslehre]' (B49). Kant makes a point here of not invoking the empirical concept of matter, conceiving of alteration and motion in the abstract (B48).

35 Kant's appeal to geometry in the Transcendental Exposition is all the more striking, given that it is arguably emphasized in the second edition (1787) version, which appeared after these remarks on the Critique's methodology in the 1783 Prolegomena. For it is only in the second edition version that Kant explicitly divides the exposition into 'metaphysical' and 'transcendental' phases; simply marking that division would, it seems, draw extra attention to the Transcendental Exposition's appeal to geometry. (In the first edition, a version of the second edition's Transcendental Exposition is sandwiched in between what later became the second and third moments of the exposition of space; see A24.) 
Critique of Judgement, Introduction $\ I V(5: 180)$; see also Critique of Pure Reason \$26 (B165).

37 This interpretation of the methodological stricture might also account for the Critique's reliance on pure general logic in the presentation of the table of categories (A70-83/B95-109). While it lies well beyond the bounds of this paper to examine the role of pure general logic in the argument of the Critique, it might prove instructive to acknowledge that the same methodological difficulty seems to arise there, too. And the resolution of the apparent methodological difficulty would run along parallel lines: just as geometry is a science of space, concerned with the 'sensible' faculty of pure general reason, so pure general logic is concerned with the 'intellectual' faculty of pure general reason. Kant can appeal to both, without flouting the restriction to take nothing as given except reason itself. (Presumably, the same point could be made with regard to the Transcendental Exposition of time's appeal to the 'general theory of motion' (B49), as well.)

38 In this passage from the Prolegomena, Kant runs together two issues that are kept distinct in the Critique. In the Transcendental Aesthetic's deduction of the concept of space, Kant draws the inference that the concept of space is necessarily applicable to objects of our cognition. The problem of the necessary applicability of mathematics to appearances is a different (but related) issue. For the former addresses the applicability of a concept to appearances, while the latter addresses the applicability of a body of cognition to appearances. The account of how mathematics is necessarily applicable to appearances depends upon the result of the transcendental deduction of the categories; in the Critique, this account is provided only later, in the Analytic of Principles - it is the point of the Axioms of Intuition and the Anticipations of Perception.

For the parallel passage regarding the concept of time, see A34-5/B51-2.

40 I am grateful to two anonymous referees for this journal, whose comments and criticisms greatly improved this paper. Thanks to Sasha Newton and Sebastian Rand for comments on an earlier version of this paper. Special thanks are due, as ever, to Markos Valaris for much discussion and for helpful comments throughout. 